\title{
Study on the Behavior of Electrochemical Extraction of Cobalt from Spent Lithium Cobalt Oxide Cathode Materials
}

\author{
Hui Li, Haotian Li, Chenxiao Li, Jinglong Liang *, Hongyan Yan and Zhengzhen Xu
}

\author{
College of Metallurgy and Energy, North China University of Science and Technology, Tangshan 063210, China; \\ lh@ncst.edu.cn (H.L.); li986496033@163.com (H.L.); lichenxiao@ncst.edu.cn (C.L.); yanhy@ncst.edu.cn (H.Y.); \\ xzz15131511868@163.com (Z.X.) \\ * Correspondence: lj1@ncst.edu.cn
}

check for updates

Citation: Li, H.; Li, H.; Li, C.; Liang, J.; Yan, H.; Xu, Z. Study on the Behavior of Electrochemical Extraction of Cobalt from Spent Lithium Cobalt Oxide Cathode Materials. Materials 2021, 14, 6110. https://doi.org/10.3390/ma14206110

Academic Editor: Piotr Piszczek

Received: 31 August 2021

Accepted: 12 October 2021

Published: 15 October 2021

Publisher's Note: MDPI stays neutral with regard to jurisdictional claims in published maps and institutional affiliations.

Copyright: (c) 2021 by the authors. Licensee MDPI, Basel, Switzerland. This article is an open access article distributed under the terms and conditions of the Creative Commons Attribution (CC BY) license (https:// creativecommons.org/licenses/by/ $4.0 /)$.

\begin{abstract}
The molten salt electrochemical method was used to reduce the Co in spent $\mathrm{LiCoO}_{2}$. The reduction mechanism of $\mathrm{Co}$ (III) in $\mathrm{LiCoO}_{2}$ was analyzed by cyclic voltammetry, square wave voltammetry, and open circuit potential. The reduction process of $\mathrm{Co}$ (III) on Fe electrode was studied in $\mathrm{NaCl}-\mathrm{CaCl}_{2}-\mathrm{LiCoO}_{2}$ molten salt system at $750{ }^{\circ} \mathrm{C}$. The results show that the reduction process of $\mathrm{Co}$ (III) is a two-step reduction: $\mathrm{Co}$ (III) $\rightarrow \mathrm{Co}$ (II) $\rightarrow \mathrm{Co}(0)$ and they are all quasi-reversible processes controlled by diffusion. Phase analysis (XRD) shows that $\mathrm{Li}^{+}$and $\mathrm{Cl}^{2-}$ in the molten salt form $\mathrm{LiCl}$ electrolysis experiments with different voltages were carried out, which proved the stepwise reduction of $\mathrm{Co}$ in $\mathrm{LiCoO}_{2}$.
\end{abstract}

Keywords: $\mathrm{NaCl}-\mathrm{CaCl}_{2}-\mathrm{LiCoO}_{2} ; \mathrm{Co}$; electrochemical test; electrolysis experiments

\section{Introduction}

Lithium-ion batteries have many excellent electrochemical properties, such as a large number of charge and discharge times and a long cycle life. In addition, lithium-ion batteries have no memory effect. As the number of recharges increases, their power storage will not decrease. Lithium-ion batteries are widely used in small and medium-sized battery industries, such as mobile phones, portable notebooks, and electric vehicles [1-3]. Therefore, people's demand for and purchase of lithium-ion batteries has increased year by year, which has led to a large number of spent lithium-ion batteries (LIBs) in the country. After three to five years of cycles, lithium-ion batteries will eventually be scrapped. By 2020, the scrap volume reached about 400 million tons [4]. Spent lithium-ion batteries are difficult to degrade and have a certain toxicity. The random disposal of used lithium-ion batteries will seriously affect the natural ecology and ultimately endanger human health. In addition, spent $\mathrm{LiCoO}_{2}$-based lithium-ion batteries contain very high-grade rare metals lithium and cobalt $[5,6]$. Therefore, the recovery of high-grade metals from waste lithium-ion batteries will have a certain improvement in the pressure on the environment and resources $[7,8]$.

Traditional methods for metal recovery from used lithium-ion batteries include pyrometallurgy, hydrometallurgy, and biometallurgy. Due to the harsh microbial culture conditions, the leached heavy metals are toxic to microorganisms, and the slow kinetics of the metallurgical process, biometallurgical methods have great limitations in commercial applications [9-11]. Pyrometallurgy is accompanied by shortcomings such as high energy consumption and strict requirements for processing equipment [12]. Hydrometallurgy uses acids and extractants to recover metals. The organic solvents used are complex and cumbersome. Excessive acid will also produce by-products such as $\mathrm{Cl}_{2}, \mathrm{SO}_{\mathrm{x}}$, and $\mathrm{NO}_{\mathrm{x}}$. This causes great pollution to the environment and does not conform to the concept of environmental protection [13-16]. Ma et al. [17] have invented a method of low-temperature chlorination pyrolysis of waste lithium-ion batteries in order to reduce energy consumption and not use acid-base agents. This method recovers valuable metals into the leaching solution in one step at $300{ }^{\circ} \mathrm{C}$, and the leaching rate is as high as $99 \%$. Zhang et al. [18] 
used pollution-free grape seeds and malic acid as the leaching night successfully recovered 92\% Co and 99\% Li from spent LIBs. Therefore, finding suitable energy saving methods has attracted widespread attention.

In recent years, the electrometallurgical technology in line with the concept of green environmental protection has received extensive attention. Chang Wei et al. [19] put the spent lithium-ion battery as the cathode in the electrolyte with anhydrous sodium sulfate as the electrolyte, and the current density, the influence of different concentrations of sulfuric acid and citric acid on the leaching of cobalt and aluminum were investigated. Finally, the current density was $15.6 \mathrm{~mA} / \mathrm{cm}^{2}$. The leaching rate of cobalt and aluminum in waste lithium-ion batteries with a concentration of $40 \mathrm{~g} / \mathrm{L}$ sulfuric acid or a concentration of $36 \mathrm{~g} / \mathrm{L}$ citric acid reached $90.8 \%$ and $7.9 \%$. In addition to the aqueous solution electrolysis of waste lithium-ion batteries, Yin Huayi et al. [20] successfully prepared metal Li and Co by electrolysis of $\mathrm{LiCoO}_{2}$ at $1023 \mathrm{~K}$ and molten salt of $\mathrm{Na}_{2} \mathrm{CO}_{3}-\mathrm{K}_{2} \mathrm{CO}_{3}$ for waste $\mathrm{LiCoO}_{2}$ based lithium-ion batteries. The metal recovery rate was $85 \%$ and $99 \%$, respectively. The electrolyzed $\mathrm{CoO}$ and $\mathrm{Li}_{2} \mathrm{CO}_{3}$ combine to form $\mathrm{LiCoO}_{2}$, so that $\mathrm{LiCoO}_{2}$ can be recycled. This simple, comprehensive and green process provide a good idea for the recovery of metallic Co from waste $\mathrm{LiCoO}_{2}$-based batteries.

When we extract metallic $\mathrm{Co}$ from $\mathrm{LiCoO}_{2}$, first we need to understand the reduction mechanism of $\mathrm{LiCoO}_{2}$ to $\mathrm{Co}$. In this paper, molten salt electrochemical method is adopted at $750{ }^{\circ} \mathrm{C}$ and $\mathrm{NaCl}-\mathrm{CaCl}_{2}-\mathrm{LiCoO}_{2}$ molten salt system are selected, combined with electrochemical test methods to analyze the $\mathrm{Co}$ (III) reduction behavior of $\mathrm{LiCoO}_{2}$ in molten salt. The electrolysis experiment of $\mathrm{LiCoO}_{2}$ with different voltages confirmed the process of $\mathrm{LiCoO}_{2}$ reduction to $\mathrm{Co}$.

\section{Experimental Method}

The raw materials are $\mathrm{LiCoO}_{2}$ (purity $\geq 99.95$ ), $\mathrm{NaCl}$ (purity $\geq 99.5$ ), and $\mathrm{CaCl}_{2}$ (purity $\geq 99.5$ ) purchased from Sinopharm Group. The corundum crucible (Zhongkehuaxueci, Tangshan, China) is used, and the main component is $\mathrm{Al}_{2} \mathrm{O}_{3}$ (purity $\geq 99.95$ ). JJ124BC electronic balance (Shuangjie, Changshu, China) is used for weighing. DZF-6020 vacuum (Boxun, Shanghai, China) drying oven is used for drying, and 3KL10.BYL resistance furnace (Yunjie, Baotou, China) is used for electrochemical test and electrolysis experiment. The electrochemical test uses the CHI660E electrochemical workstation (Chenhua, Shanghai, China) and the Noran7 X-ray diffractometer (Rigaku, Tokyo, Japan) is used for phase analysis of the raw materials and products.

The electrochemical test was carried out using a three-electrode system, iron wire (purity $\geq 99.99 \%, \Phi 1 \mathrm{~mm}$ ) chosen as the working electrode (WE) for investigating electrochemical behaviors of Co (III). The counter electrode (CE) was a smooth graphite sheet (purity $\geq 99.99 \%, 10 \mathrm{~mm} \times 5 \mathrm{~mm} \times 90 \mathrm{~mm}$ ) polished with $1500 \#-2000 \#$. The platinum wire (purity $\geq 99.999 \%$ ) in the alumina tube $(\Phi 4 \mathrm{~mm})$ was used as the reference electrode (RE). First, the $\mathrm{NaCl}$ and $\mathrm{CaCl}_{2}$ were placed in a vacuum drying (Boxun, Shanghai, China) oven at $573 \mathrm{~K}$ for $5 \mathrm{~h}$ to fully remove the moisture in $\mathrm{NaCl}$ and $\mathrm{CaCl}_{2}$. Then $200 \mathrm{~g}$ of molten salt was taken with $n \mathrm{NaCl}: n \mathrm{CaCl}_{2}=1: 1$ to crush and mix, the mixed salt was then put in the corundum crucible and moved to the drying box for drying. When using mixed salt, it is important to take out the crucible containing the mixed salt and put it into the resistance heating furnace (Yunjie, Baotou, China). The temperature was raised to $750{ }^{\circ} \mathrm{C}$ at $5^{\circ} \mathrm{C} / \mathrm{min}$, argon gas passed through the whole process for protection. When the temperature rose to $750{ }^{\circ} \mathrm{C}$, the temperature was kept constant for $1 \mathrm{~h}$ to fully dissolve the medicine, then the three electrodes were put into the upper part of the furnace tube for preheating for $10 \mathrm{~min}$ to prevent the three electrodes from being affected by extreme heat, and then insert the electrodes in the molten salt to perform the blank salt system Electrochemical detection. After the measurement, the electrode is taken out, $4 \mathrm{~g}$ of $\mathrm{LiCoO}_{2}$ powder is added to the molten salt, and the temperature is kept constant for $4 \mathrm{~h}$ to make the $\mathrm{LiCoO}_{2}$ saturated in the $\mathrm{NaCl}-\mathrm{CaCl}_{2}-\mathrm{LiCoO}_{2}$ molten salt system, and the three electrodes are placed again for electrochemical detection. 
The electrolysis experiment was carried out with a two-electrode system and $1 \mathrm{~g}$ of $\mathrm{LiCoO}_{2}$ powders were compressed into a sheet after $4 \mathrm{MPa} 2 \mathrm{~min}$. (Diameter of about $15 \mathrm{~mm}$, the thickness of about $2 \mathrm{~mm}$ ). Then it was placed in a resistance furnace and sintered at a temperature of $5{ }^{\circ} \mathrm{C} / \mathrm{min}$ to $700{ }^{\circ} \mathrm{C}$ for $10 \mathrm{~h}$ to improve the mechanical strength of the sheet. The sintered $\mathrm{LiCoO}_{2}$ pellets were then wrapped in stainless steel mesh cloth and fixed on a stainless-steel rod as a cathode, and a high-purity graphite flake (purity $\geq 99.99 \%, 10 \mathrm{~mm} \times 5 \mathrm{~mm} \times 90 \mathrm{~mm}$ ) was fixed on another stainless-steel rod as an anode. The constant cell voltage electrolysis voltage range was $0.5-1.5 \mathrm{~V}$. After the electrolysis, the cathode product was cooled with deionized water and cleaned by ultrasonic cleaning, and then placed in a drying box to dry for $12 \mathrm{~h}$. Then the product was subjected to XRD detection.

\section{Experimental Results and Discussion}

\subsection{Cyclic Voltammetry}

\subsubsection{Cyclic Voltammetry of $\mathrm{NaCl}-\mathrm{CaCl}_{2}-\mathrm{LiCoO}_{2}$}

The dotted line in Figure 1 is the $\mathrm{NaCl}-\mathrm{CaCl}_{2}$ blank experiment. From the blank experiment, the reduction and oxidation peak of the leftmost $\mathrm{DD}^{1}$ can be observed. This may be the peak corresponding to $\mathrm{Ca}^{2+}$ and $\mathrm{Ca}$ or the corresponding peak of $\mathrm{Na}^{+}$and $\mathrm{Na}$ [21], because the thermodynamic calculation software HSC Chemistry 6.0 is adopted by Formula (1). It is calculated that the theoretical decomposition voltages of $\mathrm{NaCl}$ and $\mathrm{CaCl}_{2}$ at $1023 \mathrm{~K}$ are -3.238 and $-3.325 \mathrm{~V}$, respectively, and there is not much difference between the two, which makes it difficult to distinguish the positions of peaks. When the potential range is between -2.0 and $-0.5 \mathrm{~V}$, there is no corresponding peak, so there is no oxidation-reduction reaction in the molten salt system at this time. This range can be used as the potential window after $\mathrm{LiCoO}_{2}$ is added to the $\mathrm{NaCl}-\mathrm{CaCl}_{2}$ molten salt. The red curve 2 is the $\mathrm{NaCl}-\mathrm{CaCl}_{2}$ added $\mathrm{LiCoO}_{2}$. It is shows three pairs of redox peaks, namely $\mathrm{C}(-0.5 \mathrm{~V})$ and $\mathrm{C}^{1}, \mathrm{~A}(-1.189 \mathrm{~V})$ and $\mathrm{A}^{1}, \mathrm{~B}(-1.431 \mathrm{~V})$ and $\mathrm{B}^{1}$. During the negative scanning of the potential, the current increased and a large number of active electrons accumulated on the surface of the cathode. The electrode deviated from the equilibrium potential and exhibited a polarization phenomenon, attracting $\mathrm{Li}^{+}$and $\mathrm{Co}^{3+}$ in the molten salt to the cathode, and the current gradually increased, which is the process of forming an electric double layer with the molten salt phase. When the potential was $-0.5 \mathrm{~V}$, the first reduction peak $C(-0.5 \mathrm{~V})$ appeared and the corresponding oxidation peak was $\mathrm{C}^{1}$, which is related to the process of the gas revolution reaction [22]. As the negative scanning of the potential, the potential reached the initial potential formed by peak $\mathrm{A}$, showing that a large amount of $\mathrm{Co}^{3+}$ in the molten salt diffused to the surface of the electrode. When the potential reached the energy required for $\mathrm{Co}^{3+}$ to participate in the reduction reaction, the process of $\mathrm{Co}^{3+}$ causing electrons to form $\mathrm{Co}^{2+}$ occurred on the surface of the electrode. Due to the high concentration of $\mathrm{Co}^{3+}$ near the cathode, at this time, the reaction rate was fast and the current increased. However, the generated $\mathrm{Co}^{2+}$ occupied the active sites on the electrode surface, which prevented the subsequent $\mathrm{Co}^{3+}$ diffused from the molten salt from being reduced to $\mathrm{Co}^{2+}$ on the electrode, resulting in a decrease in the reaction rate and current, which eventually formed A $(-1.189 \mathrm{~V})$ of the reduction peak current [20]. When the negative scanning potential continued to increase to the overpotential of the reduction of $\mathrm{Co}^{2+}$ on the cathode surface, the $\mathrm{Co}^{2+}$ on the electrode surface obtained electrons to form $\mathrm{Co}$, and the active sites on the electrode surface were converted to being occupied by Co. The new redox reaction made the reaction rate speed up again and the current continued to increase The $\mathrm{Co}^{2+}$ on the electrode surface gradually decreased due to the formation of Co. At the same time, the $\mathrm{Co}^{3+}$ in the molten salt could not be quickly reduced to $\mathrm{Co}^{2+}$ because the active sites were occupied by Co. The reaction to form Co was inhibited. The cumulative result of the two meant that the current was unable to continue to increase. Finally, the third reduction peak B $(-1.431 \mathrm{~V})$ appeared. Therefore, $\mathrm{LiCoO}_{2}$ in the molten salt has undergone a gradual reduction process of $\mathrm{Co}$ (III) $\rightarrow \mathrm{Co}$ (II) $\rightarrow \mathrm{Co}(0)$, which is initially certified from the blue curve 3 . The addition of $\mathrm{CoO}$ to the molten salt has some 
deviation compared with the addition of $\mathrm{LiCoO}_{2}$. The $\mathrm{Co}$ in $\mathrm{CoO}$ is +2 valence, except for the gas revolution reaction peak $\mathrm{c}$, only one reduction peak $\mathrm{b}$ appears in the curve. Therefore, it can be seen that the reduction process of $\mathrm{Co}^{2+}$ on the Fe electrode in the $\mathrm{NaCl}-\mathrm{CaCl}_{2}$ molten salt system is $\mathrm{Co}$ (II) $\rightarrow \mathrm{Co}(0)$. The number of electrons transferred by the reaction is calculated in Section 3.2.

$$
\Delta G^{\Theta}=-n F E^{\Theta}
$$

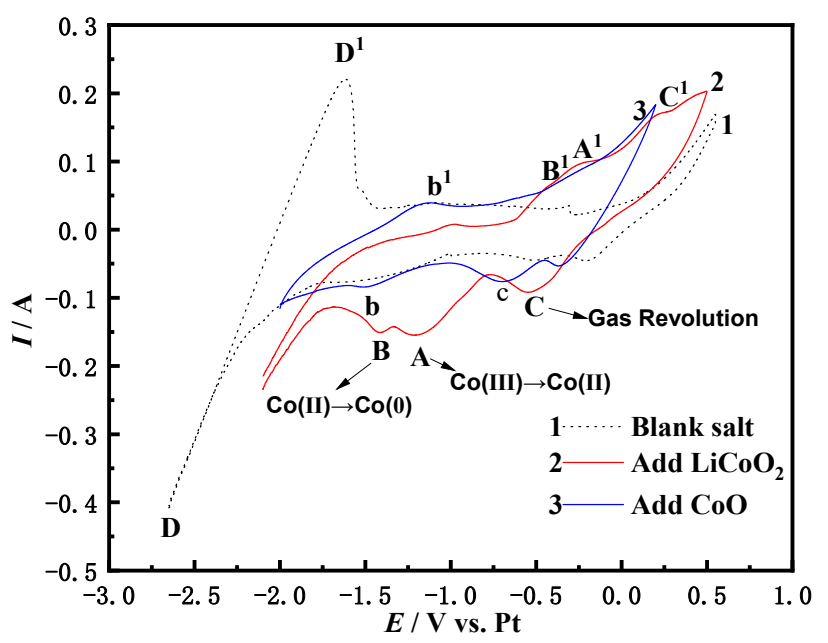

Figure 1. Cyclic voltammetry comparison of pure salt in $\mathrm{NaCl}-\mathrm{CaCl}_{2}-\mathrm{LiCoO}_{2}$ molten salt and addition of oxide (0.2 V/S; WE: Fe electrode).

\subsubsection{Cyclic Voltammetry of $\mathrm{NaCl}-\mathrm{CaCl}_{2}-\mathrm{LiCoO}_{2}$ at Different Scan Rates}

Figure 2 shows the cyclic voltammetry curves of the Fe electrode in the $\mathrm{NaCl}-\mathrm{CaCl}_{2}-$ $\mathrm{LiCoO}_{2}$ system measured at different sweep speeds at $750{ }^{\circ} \mathrm{C}$. As the scanning speed increases, the potential change per unit time is greater, the time required for electric double layer charging becomes shorter, the electrochemical reaction speed of the electrode surface is accelerated, and the current value changes more steeply, making the peak current larger.

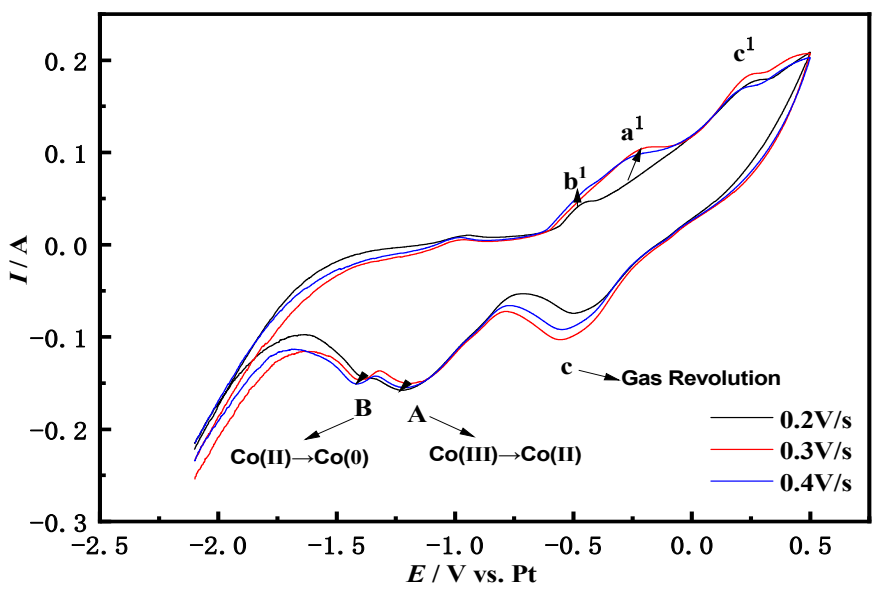

Figure 2. $\mathrm{NaCl}-\mathrm{CaCl}_{2}-\mathrm{LiCoO}_{2}$ molten salt system multi-cycle cyclic voltammetry $(0.2-0.4 \mathrm{~V} / \mathrm{s}$; Fe electrode).

The two pairs of redox peaks $\mathrm{Aa}^{1}$ and $\mathrm{Bb}^{1}$ show a slight peak shift to the negative direction for a cathodic reaction and toward the positive direction for an anodic reaction, with an increase in the scan rates revealing a quasi-reversible or irreversible. The values of the redox peak currents of peaks $\mathrm{Aa}^{1}$ and $\mathrm{Bb}^{1}$ at different sweep rates can be further judged 
by Formula (2) to determine whether the A and B reaction steps are quasi-reversible. The Equations are as follows:

$$
\left|I_{p c} / I_{p a}\right|=1
$$

It is calculated that the peak current ratio of redox peaks $\mathrm{Aa}^{1}$ and $\mathrm{Bb}^{1}$ is approximately equal to 1 . The relationship between $i_{p c}$ and $v^{1 / 2}$ of the scan rate is further determined whether it is controlled by diffusion. The $i_{p c}$ and $v^{1 / 2}$ of the reduction peaks A and B are drawn by extracting the data from the cyclic voltammetry curves of different scanning speeds, and linear fitting is performed to obtain the following Figure 3. It can be seen from the Figure 3 that the reduction peak currents of $A$ and $B$ have a linear relationship with $v^{1 / 2}$. Based on the above three criteria, it is concluded that the two reactions $\mathrm{A}$ and $\mathrm{B}$ are quasi-reversible processes and are controlled by diffusion [23].

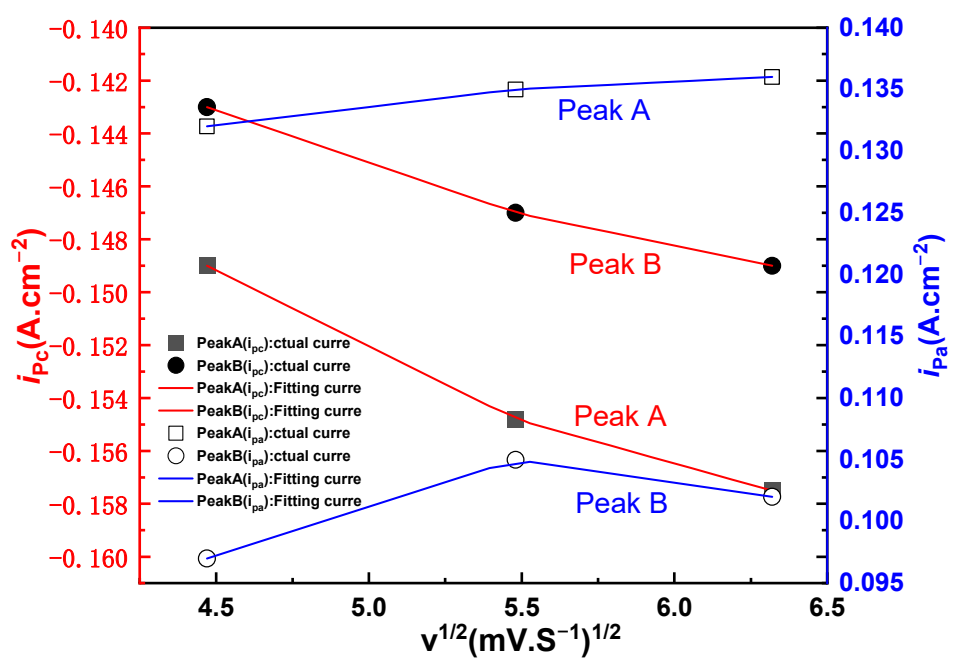

Figure 3. Relationship between $i_{p c}$ and $v^{1 / 2}$ of Fe electrode in $\mathrm{NaCl}-\mathrm{CaCl}_{2}-\mathrm{LiCO}_{2}$ molten salt system.

\subsection{Square Wave Voltammetry}

The number of electrons transferred by $\mathrm{Co}^{3+}$ on the Fe electrode was studied by the square wave voltammetry. Figure 4 shows the square wave voltammetry curve on the Fe electrode in the $\mathrm{NaCl}-\mathrm{CaCl}_{2}-\mathrm{LiCoO}_{2}$ molten salt with a frequency of $25 \mathrm{~Hz}$ and peak fitting. Two strong reduction peaks still appear on the curve: A is $-0.916 \mathrm{~V}$ and $\mathrm{B}$ is -1.6 V. Compared with the above cyclic voltammetry curve, it can be seen that the $A$ and $B$ peaks correspond to the two-step reduction of Co. According to the half-width of the quasi-reversible coincidence $\left(W_{1 / 2}\right)$ Formula (3) [24] calculates the number of transferred electrons $(n)$ of $\mathrm{Co}^{3+}$ in $\mathrm{LiCoO}_{2}$.

$$
W_{1 / 2}=3.52 \frac{R T}{n F}
$$

In the formula: $R$-molar gas constant $(8.3145 \mathrm{~J} / \mathrm{mol} / \mathrm{K}) ; T$-temperature $(\mathrm{K}) ; n-$ electron transfer number; $F$-Faraday's constant $(96,485 \mathrm{C} / \mathrm{mol})$.

According to the square wave voltammogram, the $W_{1 / 2}$ value corresponding to peak A is about $0.18 \mathrm{~V}$, and the $W_{1 / 2}$ value corresponding to peak $\mathrm{B}$ is about $0.22 \mathrm{~V}$. The number of electrons transferred by the reduction peak of A is calculated by the Formula (3) $n=0.9$, and the number of electrons transferred by the reduction peak of $\mathrm{B}$ is $n=1.5$. Therefore, it is determined that $\mathrm{Co}$ (III) is a two-step reduction process, namely:

$$
\begin{aligned}
& \mathrm{Co}(\mathrm{III})+\mathrm{e}^{-}=\mathrm{Co}(\mathrm{II}) \\
& \mathrm{Co}(\mathrm{II})+2 \mathrm{e}^{-}=\mathrm{Co}(0)
\end{aligned}
$$


The above analysis shows that the reduction process of $\mathrm{Co}$ (III) on the Fe electrode is a two-step process of obtaining electrons, Co (III) $\rightarrow$ Co (II) $\rightarrow$ Co (0), which is consistent with the conclusion of the cyclic voltammetry curve analysis.

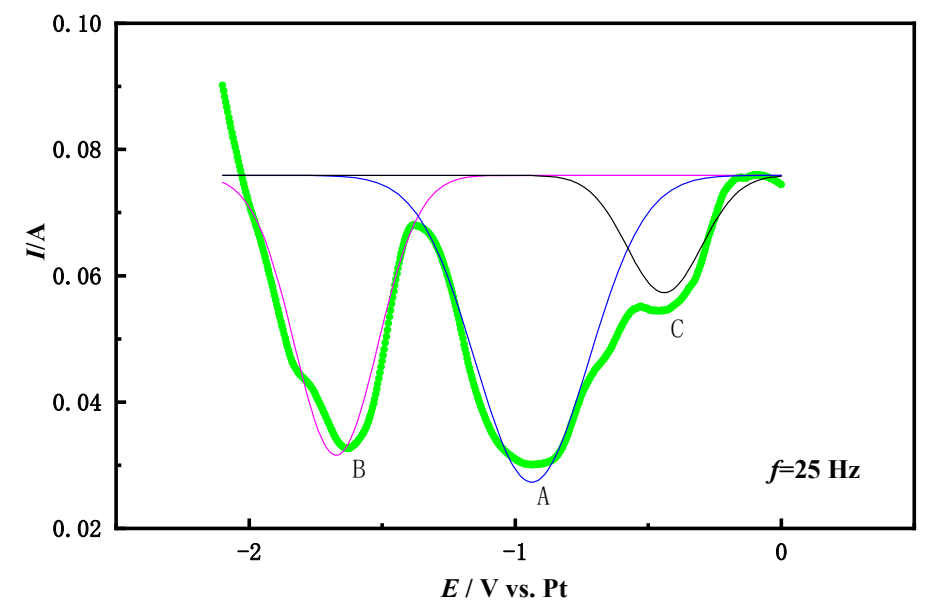

Figure 4. Square wave voltammetry of $\mathrm{NaCl}-\mathrm{CaCl}_{2}-\mathrm{LiCoO}$ molten salt system $(25 \mathrm{~Hz}$; Fe electrode).

\subsection{Open Circuit Chronopotential}

The reduction step of $\mathrm{LiCoO}_{2}$ is judged from the number of platforms where the open circuit potential appears. Figure 5 shows the open circuit in the $\mathrm{NaCl}-\mathrm{CaCl}_{2}-\mathrm{LiCoO}_{2}$ molten salt system. First apply $-1.5 \mathrm{~V}$ voltage to the working electrode for polarization for the $60 \mathrm{~s}$, so that the working electrode has higher energy to convert $\mathrm{LiCoO}_{2}$ into metal $\mathrm{Co}$, and then perform an open circuit potential test. It can be seen from the Figure 5 that there are three obvious platforms. Platform B first appears on the surface of the working electrode. Its potential is $-1.025 \mathrm{~V}$, which corresponds to the peak B in the cyclic voltammetry curve. The reaction here is $\mathrm{Co}(0) \rightarrow \mathrm{Co}$ (II). As time goes by, the concentration of $\mathrm{Co}^{2+}$ keeps increasing, and the electrode potential keeps decreasing. When the potential decreases to the potential for $\mathrm{Co}^{2+}$ oxidation reaction, the second plateau $\mathrm{A}$ is reached at this time, and its potential is $-1.01 \mathrm{~V}$, which corresponds to the potential of peak $\mathrm{A}$ in the cycle voltammetry. The reaction occurring is $\mathrm{Co}$ (II) $\rightarrow \mathrm{Co}$ (III).

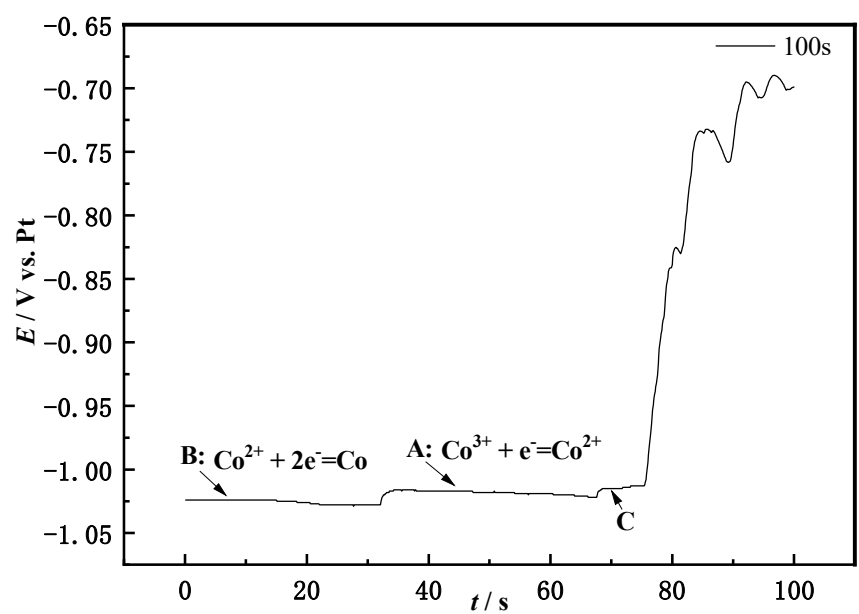

Figure 5. Open circuit chronopotential of $\mathrm{NaCl}-\mathrm{CaCl}_{2}-\mathrm{LiCoO}_{2}$ molten salt system (100 s; Fe electrode).

\subsection{Cyclic Voltammetry of $\mathrm{Li}_{2} \mathrm{O}$ in $\mathrm{NaCl}-\mathrm{CaCl}_{2}$}

The two-step reduction of $\mathrm{Co}$ (III) $\rightarrow \mathrm{Co}$ (II) $\rightarrow \mathrm{Co}(0)$ in $\mathrm{LiCoO}_{2}$ has been verified from multiple angles such as cyclic voltammetry, square wave voltammetry and open-circuit chronopotential. However, the $\mathrm{Li}^{+}$fate problem is not obtained by the above method. 
Figure 6 shows the comparison of cyclic voltammetry between adding $\mathrm{Li}_{2} \mathrm{O}$ and $\mathrm{LiCoO}_{2}$ in molten salt. It can be seen from Figure 6 that the cyclic voltammetry curve of adding $\mathrm{Li}_{2} \mathrm{O}$ in molten salt has no redox peak in the potential window. This is because the theoretical decomposition voltage of $\mathrm{Li}$ is more negative than that of $\mathrm{Co}$ and $\mathrm{Fe}$. Equation (6) combined with Equation (1) calculates the decomposition voltage of $\mathrm{Li}_{2} \mathrm{O}$ as $-2.34 \mathrm{~V}$, which means that its reduction occurs after Fe and $\mathrm{Co}$. Therefore, during the electrochemical scanning process, the redox peak of Li did not appear. According to Equations (7) and (8) and Figure 7, XRD analysis of the molten salt near the cathode after electrolysis, it can be concluded that $\mathrm{Li}^{+}$will eventually dissolve spontaneously into the molten salt to form $\mathrm{LiCl}$.

$$
\begin{gathered}
4 \mathrm{Li}+\mathrm{O}_{2}=2 \mathrm{Li}_{2} \mathrm{O} \Delta \mathrm{G}^{\Theta}=-923.7115 \mathrm{~kJ} / \mathrm{mol} \\
\mathrm{Li}_{2} \mathrm{O}+2 \mathrm{NaCl}=2 \mathrm{LiCl}+\mathrm{Na}_{2} \mathrm{O} \Delta \mathrm{G}^{\Theta}=164.5 \mathrm{~kJ} / \mathrm{mol} \\
\mathrm{Li}_{2} \mathrm{O}+\mathrm{CaCl}_{2}=2 \mathrm{LiCl}+\mathrm{CaO} \Delta \mathrm{G}^{\Theta}=-80.7 \mathrm{~kJ} / \mathrm{mol}
\end{gathered}
$$

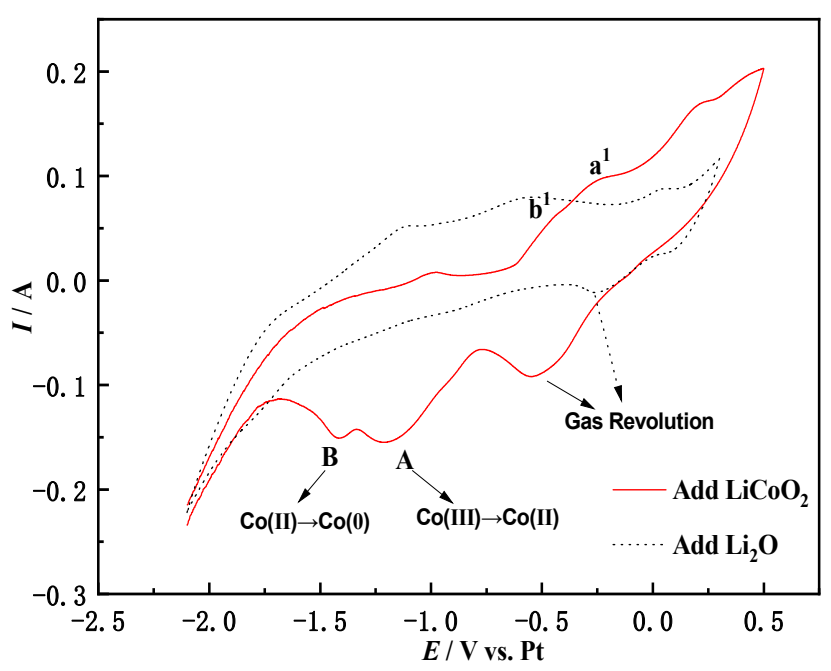

Figure 6. Comparison of cyclic voltammetry curves after addition of $\mathrm{Li}_{2} \mathrm{O}$ with $\mathrm{LiCoO}_{2}\left(\mathrm{CaCl}_{2}-\mathrm{NaCl}\right.$ system $0.2 \mathrm{~V} / \mathrm{S}$ Fe electrode).

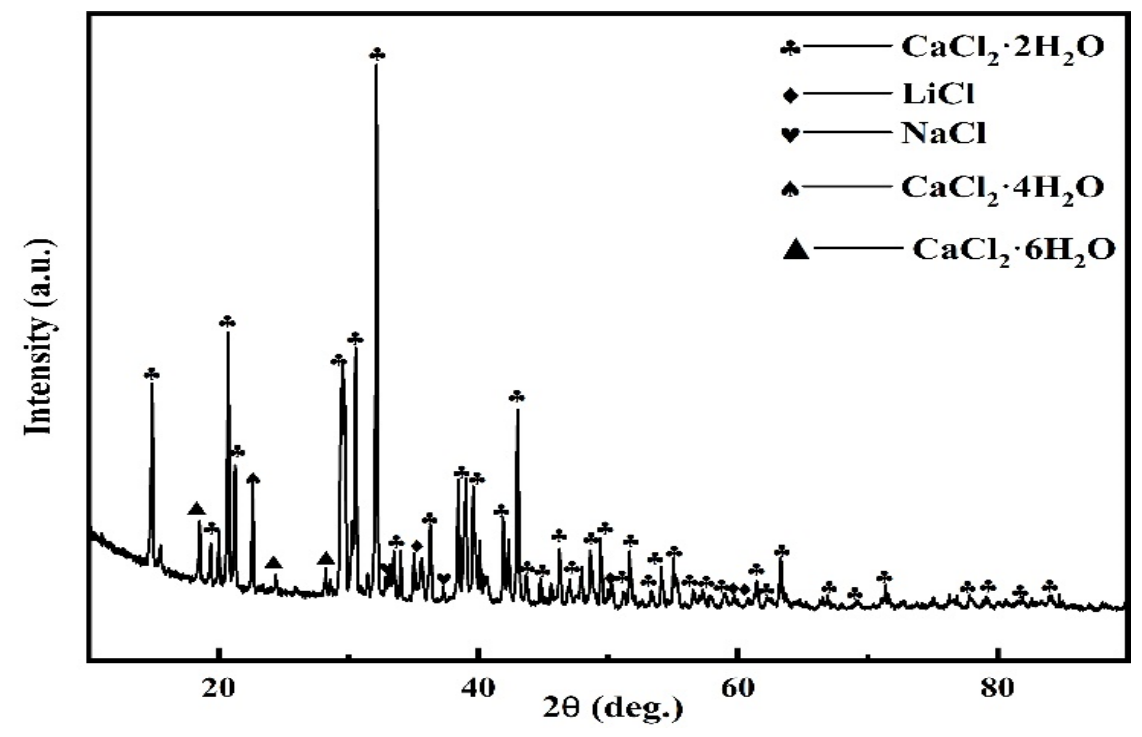

Figure 7. XRD detection of molten salt near the cathode after electrolysis. 


\subsection{Preparation of Co by Electrolysis of $\mathrm{LiCoO}_{2}$ at Constant Cell Pressure}

3.5.1. Immersion Test of $\mathrm{LiCoO}_{2}$ in $\mathrm{NaCl}-\mathrm{CaCl}_{2}$ Molten Salt

The sintered $1 \mathrm{~g} \mathrm{LiCoO}_{2}$ sheet was made into a cathode, and soaked in $\mathrm{NaCl}-\mathrm{CaCl}_{2}$ molten salt at $750{ }^{\circ} \mathrm{C}$ for $2 \mathrm{~h}$ to complete the immersion experiment, and explore whether it would have a chemical reaction in the molten salt; the XRD of the immersion experiment is shown in Figure 8, and it was found $\mathrm{LiCoO}_{2}$ did not react after being immersed for $2 \mathrm{~h}$. It can be seen that $\mathrm{LiCoO}_{2}$ is physically dissolved in molten salt. After eliminating the interference of molten salt on the raw material $\mathrm{LiCoO}_{2}$, electrolysis experiments were carried out under different voltage conditions.
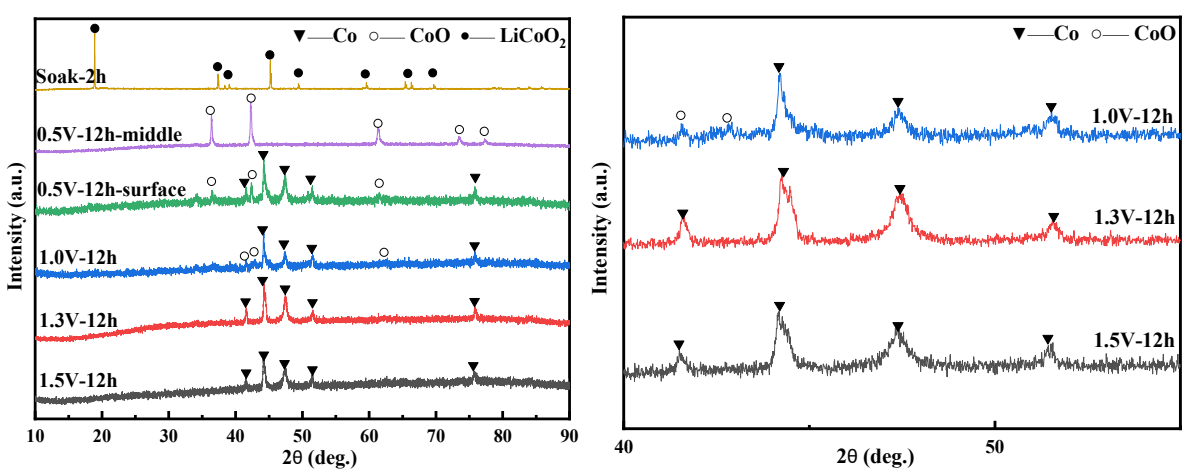

Figure 8. XRD of products electrolyzed at different voltages for $12 \mathrm{~h}$.

\subsubsection{The Influence of Voltage Conditions on Electrolysis}

It can be seen in Figure 8 that $\mathrm{CoO}$ and metallic Co were formed on the surface of the cathode sheet at $0.5 \mathrm{~V}$ and $12 \mathrm{~h}$, while the internal products were all CoO. Figure 9 more intuitively shows that the surface of the cathode of the $0.5 \mathrm{~V}$ product is gray in $\mathrm{Co}$, while the inside of the product shows a black color containing a mixture of $\mathrm{CoO}$ and $\mathrm{Co}$. This reduction process conforms to the 3PIs reaction model. The electrolysis reaction slowly extends from the three contact points of the current collector $/ \mathrm{LiCoO}_{2}$ sheet $/$ molten salt to the entire cathode surface. The internal $\mathrm{O}^{2-}$ removal path becomes longer, and the reaction speed is slower than the cathode surface. Therefore, $0.5 \mathrm{~V}, 12 \mathrm{~h}$ shows Co production on the outside and $\mathrm{CoO}$ on the inside. This also confirms the two reduction processes of $\mathrm{LiCoO}_{2}$. In Figure 9, the anode graphite sheet gradually becomes rough with the increase in voltage, indicating that $\mathrm{O}^{2-}$ diffuses faster in the reaction, and more $\mathrm{O}^{2-}$ diffuses to the anode to discharge. When the voltage rises to $1.3 \mathrm{~V}$, all $\mathrm{LiCoO}_{2}$ is reduced to $\mathrm{Co}$. In addition, when the voltage is increased to $1.5 \mathrm{~V}$, the characteristic peak width of the electrolytic product Co is smaller, indicating that Co has undergone a longer crystal growth stage during the reaction time, and its crystal size is larger than that in the $1.3 \mathrm{~V}$ product.
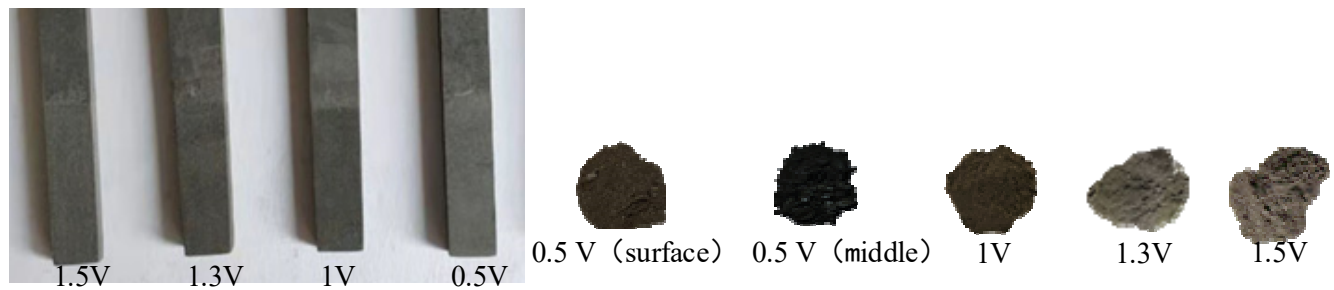

Figure 9. Images of anode (left is graphite sheet) and cathode (right is products after electrolysis) products of graphite rods electrolyzed at different voltages for $12 \mathrm{~h}$.

\section{Conclusions}

(1) When the potential is within $-2.6 \mathrm{~V} \sim 0.5 \mathrm{~V}$, two pairs of redox peaks appear, indicating that the reduction of $\mathrm{Co}$ (III) is a two-step process, Co (III) $\rightarrow$ Co (II) $\rightarrow$ Co (0). In the first step, the $\mathrm{Co}_{\mathrm{O}}$ (III) in the molten salt is reduced to Co (II) by an electron on the 
surface of the Fe electrode, and the second step is that Co (II) on the active site of the Fe electrode is reduced to $\mathrm{Co}(0)$ by two electrons. The reduction process of $\mathrm{LiCoO}_{2}$ is a quasi-reversible reaction controlled by diffusion. $\mathrm{Li}^{+}$forms $\mathrm{LiCl}$ with $\mathrm{Cl}^{-}$in molten salt during electrochemical reaction.

(2) Electrolysis experiments with different voltages of 0.5-1.5 V have confirmed the two-part reduction process of $\mathrm{LiCoO}_{2}$. The reduction reaction first proceeds on the three-phase boundary of the current collector $/ \mathrm{LiCoO}_{2}$ sheet $/ \mathrm{molten}$ salt contact, and then extends to the entire cathode surface. The inside of the $\mathrm{LiCoO}_{2}$ sheet reaction speed is slower than the surface. The inside of the $\mathrm{LiCoO}_{2}$ sheet is all $\mathrm{CoO}$, which is the first reduction product, while $\mathrm{CoO}$ and $\mathrm{Co}$ are present on the outside at $0.5 \mathrm{~V}, 12 \mathrm{~h}$. When the voltage reaches $1.3 \mathrm{~V}$, the $\mathrm{LiCoO}_{2}$ sheet is reduced to Co.

Author Contributions: Conceptualization, J.L., H.L. (Hui Li); methodology, H.Y., H.L. (Haotian Li); validation, C.L., H.Y.; investigation, J.L., H.L. (Hui Li); resources, Z.X., H.L. (Haotian Li). All authors have read and agreed to the published version of the manuscript.

Funding: This research was funded by the National Natural Science Foundation of China (No. 51774143).

Institutional Review Board Statement: Not applicable.

Informed Consent Statement: Not applicable.

Data Availability Statement: Data sharing is not applicable to this article.

Conflicts of Interest: The authors declare no conflict of interest. The funders had no role in the design of the study; in the collection, analyses, or interpretation of data; in the writing of the manuscript, or in the decision to publish the results.

\section{References}

1. Xu, Y.N.; Dong, Y.Y.; Han, X.; Wang, X.F.; Wang, Y.J.; Jiao, L.F.; Yuan, H.T. Application for Simply Recovered LiCoO 2 Material as a High Performance Candidate for Supercapacitor in Aqueous System. ACS Sustain. Chem. Eng. 2015, 3, 2435-2442. [CrossRef]

2. Takacova, Z.; Havlik, T.; Kukurugya, F.; Orac, D. Cobalt and lithium recovery from active mass of spent Li-ion batteries: Theoretical and experimental approach. J. Hydrometall. 2016, 163, 9-17. [CrossRef]

3. Ma, Y.Y.; Tang, J.J.; Wanaldi, R.; Zhou, X.Y.; Wang, H.; Zhou, C.Y.; Yang, J. A promising selective recovery process of valuable metals from spent lithium-ion batteries via reduction roasting and ammonia leaching. J. Hazard. Mater. 2021, $402,123491$. [CrossRef]

4. Sethurajan, M.; Gaydardzhi, E.S. Bioprocessing of spent lithium-ion batteries for critical metals recovery-A review. J. Res. Conserv. Recycl. 2020, 165, 105225. [CrossRef]

5. Chen, X.P.; Guo, C.X.; Ma, H.R.; Li, J.Z.; Zhou, T.; Cao, L.; Kang, D. Organic reductants based leaching: A sustainable process for the recovery of valuable metals from spent lithium ion batteries. J. Was. Manag. 2018, 75, 459-468. [CrossRef] [PubMed]

6. Chagnes, A.; Pospiech, B. A brief review on hydrometallurgical technologies for recycling spent lithium-ion batteries. J. Chem. Technol. Biotechnol. 2013, 88, 1191-1199. [CrossRef]

7. Meng, Q.; Zhang, Y.J.; Dong, P.; Liang, F. Recovery of Co and Li from spent lithium ion batteries. J. ISSN 2017, 36, 3485-3491. [CrossRef]

8. Dorella, G.; Mansur, M.B. A study of the separation of cobalt from spent Li-ion battery residues. J. Power Sources 2007, 170, 210-215. [CrossRef]

9. Xin, B.P.; Zhang, D.; Zhang, X.; Xia, Y.T.; Wu, F.; Chen, S.; Li, L. Bioleaching mechanism of Co and Li from spent lithium-ion battery by the mixed culture of acidophilic sulfur-oxidizing and iron-oxidizing bacteria. J. Bioresour. Technol. 2009, 100, 6163-6169. [CrossRef] [PubMed]

10. Zhang, L.; Qiu, G.Z.; Hu, Y.H.; Sun, X.J.; Li, J.H.; Gu, G.H. Bioleaching of pyrite by A.ferrooxidans and L.ferriphilum. Trans. Nonferrous. Met. Soc. China 2008, 18, 1415-1420. [CrossRef]

11. Işıldar, A.; Hullebusch, E.; Lenz, M.; Laing, G.D.; Cesaro, A.; Panda, S.; Akcil, A.; Kucuker, M.A.; Kuchta, K. Biotechnological strategies for the recovery of valuable and critical raw materials from waste electrical and electronic equipment (WEEE) - A review. J. Hazard. Mater. 2019, 362, 467-481. [CrossRef] [PubMed]

12. Lv, W.G.; Wang, Z.H.; Cao, H.B.; Sun, Y.; Zhang, Y.; Sun, Z. A Critical Review and Analysis on the Recycling of Spent Lithium-Ion Batteries. ACS Sustain. Chem. Eng. 2018, 6, 1504-1521. [CrossRef]

13. He, L.P.; Sun, S.; Mu, Y.Y.; Song, X.; Yu, J. Recovery of lithium, nickel, cobalt, and manganese from spent lithium-ion batteries using L-tartaric acid as a leachant. ACS Sustain. Chem. Eng. 2017, 5, 714-721. [CrossRef]

14. Bai, Y.C.; Muralidharan, N.; Sun, Y.K.; Passerini, S.; Stanley, W.M.; Belharouak, L. Energy and environmental aspects in recycling lithium-ion batteries: Concept of Battery Identity Global Passport. J. Mater. 2020, 41, 304-315. [CrossRef] 
15. Qian, W.; Zhang, W.Y.; Dong, H.X.; Shi, H. Experimental Study on Ultrasonic Leaching of Cobalt from Waste Lithium-ion Battery with. J. Chem. Ind. 2021, 48, 48-49+84.

16. Sun, L.Y.; Liu, B.R.; Wu, T.; Wang, G.G.; Huang, Q.; Su, Y.F.; Wu, F. Hydrometallurgical recycling of valuable metals from spent lithium-ion batteries by reductive leaching with stannous chloride. Int. J. Miner. Metal. Mater. 2021, 28, 997-1000.

17. Ma, Y.Y.; Zhou, X.Y.; Tang, J.J.; Liu, X.J.; Gan, H.X.; Yang, J. One-step selective recovery and cyclic utilization of valuable metals from spent lithium-ion batteries via low-temperature chlorination pyrolysis. J. Resour. Conserv. Recycl. 2021, 175, 105840. [CrossRef]

18. Zhang, Y.J.; Meng, Q.; Dong, P.; Duan, J.G.; Lin, Y. Use of grape seed as reductant for leaching of cobalt from spent lithium-ion batteries. J. Ind. Eng. Chem. 2018, 66, 86-93. [CrossRef]

19. Chang, W.; Man, R.L.; Yi, X.Y.; Zhang, J. Leaching $\mathrm{LiCoO}_{2}$ from spent lithium-ion batteries by electrochemical reduction. Chin. J. Nonferrous. 2014, 24, 787-792. [CrossRef]

20. Zhang, B.L.; Xie, H.W.; Lu, B.H.; Chen, X.; Xing, P.F.; Qu, J.K.; Song, Q.S.; Yin, H.Y. A Green Electrochemical Process to Recover $\mathrm{Co}$ and $\mathrm{Li}$ from Spent $\mathrm{LiCoO}_{2}$-Based Batteries in Molten Salts. ACS Sustain. Chem. Eng. 2019, 7, 13391-13399. [CrossRef]

21. Rong, L.B.; He, R.; Wang, Z.Y.; Peng, J.J.; Jin, X.B.; Chen, G.Z. Investigation of electrochemical reduction of $\mathrm{GeO}_{2}$ to Ge in molten $\mathrm{CaCl}_{2}-\mathrm{NaCl}$. J. Electrochim. Acta 2014, 147, 352-359. [CrossRef]

22. Weng, W.; Wang, M.Y.; Gong, X.Z.; Wang, Z.; Wang, D.; Guo, Z.C. Direct electro-deposition of metallic chromium from $\mathrm{K}_{2} \mathrm{CrO}_{4}$ in the equimolar $\mathrm{CaCl}_{2}-\mathrm{KCl}$ molten salt and its reduction mechanism. Electrochim. Acta 2016, 212, 162-170. [CrossRef]

23. Li, C.Y.; Han, W.; Li, M.; Wang, W.; Yang, X.G. Electrochemistry of Zr (IV) in molten LiCl-KCl-K ${ }_{2} \mathrm{ZrF}_{6}$ system. Int. J. Electrochem. Sci. 2018, 13, 11795-11807. [CrossRef]

24. Li, M.; Xi, X.L.; Nie, Z.R.; Ma, L.W.; Liu, Q.Q. Recovery of tungsten from WC-Co hard metal scraps using molten salts electrolysis. J. Mater. Res. Technol. 2018, 8, 1440-1450. [CrossRef] 